\title{
Effect of meal frequency and timing on physical performance
}

\author{
BY JOHN A. HAWLEY ${ }^{1}$ AND LOUISE M. BURKE ${ }^{2}$ \\ ${ }^{1}$ MRC/UCT Bioenergetics of Exercise Research Unit, Department of Physiology, University of Cape \\ Town Medical School, South Africa \\ ${ }^{2}$ Department of Sports Nutrition, Australian Institute of Sport, Belconnen ACT 2616, Australia
}

Two areas of sports nutrition in which the periodicity of eating has been studied relate to: (1) the habitually high energy intakes of many athletes, and (2) the optimization of carbohydrate (CHO) availability to enhance performance. The present paper examines how the timing and frequency of food and fluid intake can assist the athlete and physically-active person to improve their exercise performance in these areas. Frequent eating occasions provide a practical strategy allowing athletes to increase energy intake while concomitantly reducing the gastric discomfort of infrequent large meals. The optimization of CHO stores is a special challenge for athletes undertaking prolonged training or competition sessions. This is a cyclical process with post-exercise CHO ingestion promoting muscle and liver glycogen re-synthesis; pre-exercise feedings being practised to optimize substrate availability and feedings during exercise providing a readily-available source of exogenous fuel as endogenous stores become depleted. The timing and frequency of CHO intake at these various stages are crucial determinants for optimizing fuel availability to enhance exercise capacity.

Meal frequency: Meal timing: Carbohydrate intake: Physical performance

Reviews of dietary guidelines for athletes (American Dietetic Association, 1993; Burke \& Hawley, 1997a) have identified a number of nutritional goals for optimal physical performance, including issues relating to everyday eating as well as acute strategies to enhance key exercise sessions. To date, research in these areas has focused on identifying and quantifying the energy requirements of various sporting activities. Despite evidence from other areas of nutrition research that physiological and metabolic responses during exercise can be manipulated by altering meal frequency and timing, the study of the pattern of food intake to provide these requirements has received far less attention.

Two areas in which the periodicity of eating has been extensively studied relate to the habitually high energy intakes of many athletes, and the optimization of carbohydrate (CHO) availability to enhance performance. Accordingly, the aim of the present paper is to examine how the timing and frequency of food and fluid intake can assist the physicallyactive person to improve their exercise capacity via the application of appropriate and scientifically-based nutritional strategies in these areas.

\section{PERIODICITY OF EATING TO MEET TOTAL ENERGY REQUIREMENTS}

The most basic nutritional concern for individuals undertaking strenuous physical activity is the excess of energy expended above the normal daily energy expenditure. Whereas the untrained individual has an energy expenditure of $8.5-10.5 \mathrm{MJ} / \mathrm{d}$ (Brotherhood, 1984), athletes undergoing strenuous training often have energy expenditures two to three times greater than this, with the energy cost of training being as much as $40 \%$ of their total energy expenditure (Danforth, 1985). Athletes also incur extremely high energy requirements due to their large body size, periods of growth and muscular development, or a combination of these factors. The reported energy intakes of athletes are variable and 
susceptible to a number of methodological errors; nevertheless, typical mean energy intakes for groups with high energy requirements range from 15 to $25 \mathrm{MJ} / \mathrm{d}$ for males (De Wijn \& Van Erp-Baart, 1980; Barry et al. 1981; Short \& Short, 1983; Van Erp-Baart et al. 1989; Burke et al. 1991) and from 10 to $17 \mathrm{MJ} / \mathrm{d}$ for females (De Wijn \& Van Erp-Baart, 1980; Barry et al. 1981; Short \& Short, 1983; Fogelholm et al. 1992).

In addition to high energy requirements, athletes undertaking prolonged moderate to high ( $>70 \%$ of maximal $\mathrm{O}_{2}$ uptake $\left(V_{\mathrm{O}_{2} \max }\right)$ intensity exercise have greatly increased CHO needs; extra $\mathrm{CHO}$ is necessary to optimize fuel availability during training sessions, and to promote post-exercise muscle glycogen re-synthesis. Dietary records from cyclists competing in the Tour de France revealed a mean total energy intake of $24.3 \mathrm{MJ} / \mathrm{d}$, with a CHO intake of $12.3 \mathrm{~g} / \mathrm{kg}$ body mass (BM) per d (Saris et al. 1989). Since CHO is less energy dense than lipid, and many $\mathrm{CHO}$-rich foods are bulky and fibre-rich, a high-CHOhigh-energy diet entails a large food volume and considerable eating time.

Although the relationship between energy intake and frequency of eating has not been systematically studied in athletes, a number of dietary surveys have commented on the 'grazing' food patterns or high frequency of food consumption in athletes who report large energy intakes (De Wijn \& Van Erp-Baart, 1980; Khoo et al. 1987; Van Erp-Baart et al. 1989; Lindeman, 1990; Burke et al. 1991; Hawley \& Williams 1991; Butterworth et al. 1994). Burke et al. (1991) commented on the pattern of five to six eating occasions daily by triathletes and runners, while Lindeman (1990) observed that the triathletes she surveyed reported an average of nine eating occasions daily. Hawley \& Williams (1991) noted that more the $90 \%$ of their sample of age-group swimmers consumed snacks between meals, while runners and cyclists typically report an average of eight to ten eating occasions daily, with an inverse relationship between energy intake and the time interval between eating (Kirsch \& Von Ameln, 1981). It appears that eating a series of small meals and snacks over the course of the day is a practical strategy which allows increased energy intake, while also reducing the gastric discomfort of infrequent large meals.

In the majority of these dietary studies of the nutritional practices of active individuals, the definition of an eating occasion and the distinction between 'meals' and 'snacks' have not been made clear. However, for the most part meals were defined according to culturally-based determinants such as the time of day of eating and the types of foods consumed. When these definitions are used, the estimated contribution of 'between meal snacks' to the total daily intake is high and consistent across a variety of athletic populations, accounting for approximately one-third of total daily energy intake (De Wijn \& Van Erp-Baart, 1980; Khoo et al. 1987; Van Erp-Baart et al. 1989; Butterworth et al. 1994). While frequency of eating provides an important aid to the challenge of high energy requirements, food selection should also be considered. When energy and, in particular, $\mathrm{CHO}$ needs are high the composition of meals and snacks should favour the inclusion of less-bulky forms of $\mathrm{CHO}$ such as commercially-available CHO drinks, and foods rich in simple sugars.

An important observation from several of the investigations which have reported very high energy intakes in athletes is that a significant amount of the daily nutrient intake may be consumed while the individual is exercising; considering the extremely high daily energy requirements, such athletes need to use all available opportunities in order to meet their energy needs, including the time taken for training or competing. For example, $\mathrm{CHO}-$ rich foods and drinks consumed while riding provided nearly $50 \%$ of the total energy, and $60 \%$ of the daily $\mathrm{CHO}$ intake of cyclists competing in the Tour de France (Saris et al. 1989). Only by adopting such a nutritional regimen can these cyclists maintain energy balance over the $20 \mathrm{~d}$ of the Tour during which they ride over $4000 \mathrm{~km}$. Suitable food 
choices to attain such goals include concentrated sports drinks and portable CHO-rich foods such as fruit, confectionery, bread, cakes and bars.

Although individuals participating in non-weight-bearing sports consume significant amounts of energy while training or competing, in many events the mode and intensity of exercise effectively prevent the consumption of nutrients other than sports drinks which typically have an CHO content of only $50-70 \mathrm{~g} / 1$. As a result some athletes may find that practical issues associated with their exercise schedule challenge their ability to meet daily energy and nutrient requirements. The fear of gastrointestinal discomfort and the reduced access to foods and fluid may limit intake both during the exercise bout and also for up to $3 \mathrm{~h}$ before the session. Many individuals also report diminished appetite in the $2-3 \mathrm{~h}$ immediately after strenuous exercise. Such persons may require nutritional counselling to find additional opportunities for energy and nutrient intake, and to identify foods and drinks which are specially suited to their unique circumstances.

\section{CARBOHYDRATE AVAILABILITY AND EXERCISE CAPACITY}

$\mathrm{CHO}$ is the predominant source of energy for muscle metabolism during short $(<60 \mathrm{~s})$ bouts of supra-maximal work (Saltin \& Karlsson, 1971) and the preferred fuel for muscle for prolonged, moderate-intensity exercise lasting up to $4 \mathrm{~h}$ (Hawley \& Hopkins, 1995). Unfortunately, however, the total reserves of endogenous $\mathrm{CHO}$ are limited to $8-10 \mathrm{MJ}$ in the healthy individual and are often substantially less than the fuel requirements of many athletic events. Therefore, an important concern for the athlete is to match CHO availability to the requirements of training and competition. The optimization of $\mathrm{CHO}$ stores is a special challenge for athletes who undertake prolonged exercise sessions. This is a cyclic process, with post-exercise $\mathrm{CHO}$ ingestion promoting muscle and liver glycogen re-synthesis in order to maximize endogenous $\mathrm{CHO}$ stores for the subsequent training session; pre-exercise feedings being practised to 'top up' and fine-tune substrate availability; and feedings during exercise providing a readily-available source of exogenous fuel as endogenous stores become depleted. The timing and frequency of $\mathrm{CHO}$ intake at these various stages are crucial determinants for optimizing fuel availability to enhance exercise capacity. While it should be noted that investigations measuring the direct effect of such strategies on exercise performance are rare, there is evidence that the manipulation of eating schedules may be important to achieve specific goals of sports nutrition both in daily training and in the acute or competition setting. These will now be discussed.

\section{TIMING OF PRE-EXERCISE FEEDINGS TO INCREASE CARBOHYDRATE AVAILABILITY}

The goals of pre-exercise nutrition are to optimize muscle and liver glycogen stores; to avoid gastrointestinal discomfort during exercise; and to avoid the exaggerated increase in plasma insulin concentrations that sometimes result in rebound-hypoglycaemia in susceptible individuals. The pre-exercise period is defined here as the $4 \mathrm{~h}$ period before an event and has been divided into two metabolically-significant stages: the $2-4 \mathrm{~h}$ preexercise and the $30-60 \mathrm{~min}$ period pre-exercise.

The importance of $2-4 \mathrm{~h}$ pre-exercise feedings for enhancing fuel status largely depends on the degree of recovery since the previous exercise session. Athletes who have reduced their exercise regimen and consumed a CHO-rich diet for 2-3 d before competition ('CHO-loading') will increase their muscle glycogen stores significantly (Sherman et al. 
1981). However, athletes undertaking strenuous daily training or competition may enter the pre-exercise period with sub-optimal muscle and liver fuel stores.

A CHO-rich meal consumed $4 \mathrm{~h}$ before exercise significantly increases muscle and liver glycogen content which may have been suppressed by previous exercise or an overnight fast (Coyle et al. 1985). Furthermore, the intake of a substantial amount of CHO (approximately $300 \mathrm{~g}$ ) $4 \mathrm{~h}$ before exercise by fasted subjects improved the time taken to complete a fixed amount of work following prolonged, moderate-intensity cycling, compared with when subjects did not ingest CHO (Sherman et al. 1989). Similar results of enhanced endurance (Wright et al. 1991) and work output at the end of a standardized exercise bout (Neufer et al. 1987) have been reported when large ( $>200 \mathrm{~g})$ meals were consumed in the $3-4 \mathrm{~h}$ before moderate-intensity cycling. Elevation of muscle glycogen content provides one mechanism to explain performance improvements; however, $\mathrm{CHO}$ availability is also improved via restoration of liver glycogen stores and the storage of glucose in the gastrointestinal space for later release. Since liver glycogen stores are labile and may be substantially depleted by an overnight fast, pre-exercise $\mathrm{CHO}$ intake on the morning of an event may be important for maintaining euglycaemia via hepatic glucose output during the latter stages of prolonged exercise.

One hypothesized disadvantage of pre-exercise $\mathrm{CHO}$ feedings, however, is the elevation of plasma insulin concentrations which would be expected to suppress fat metabolism while concomitantly accelerating $\mathrm{CHO}$ oxidation and causing a decline in plasma glucose concentrations during subsequent exercise. Such metabolic alterations have been observed when feedings were given $4 \mathrm{~h}$ before exercise, and persist even though plasma glucose and insulin concentrations had normalized by the onset of exercise (Coyle et al. 1985). However, such metabolic perturbations do not appear detrimental to performance. More importantly, the increase in $\mathrm{CHO}$ availability associated with large preexercise feedings more than offsets the increase in exercise CHO utilization.

Compared with the unfed state, the consumption of CHO in the $30-60 \mathrm{~min}$ period before exercise causes a pronounced elevation in plasma glucose and insulin concentrations at the onset of exercise. Foster et al. (1979) reported that feeding $75 \mathrm{~g}$ glucose $30 \mathrm{~min}$ before exercise impaired cycle time to exhaustion at $80 \%$ of $V_{\mathrm{O}_{2} \max }$ but did not alter the length of time subjects were able to ride during more intense $\left(100 \%\right.$ of $\left.V_{\mathrm{O}_{2} \max }\right)$ exercise. They observed a rapid drop in blood glucose concentration during the first $10 \mathrm{~min}$ of exercise after subjects had been fed $\mathrm{CHO}$, but noted that this response was transient and was not associated with fatigue. Although muscle glycogen content was not determined, the reduction in endurance following $\mathrm{CHO}$ feeding was attributed to an accelerated muscle glycogenolysis (Foster et al. 1979).

Unfortunately the results of this study have been so widely reported and publicised that warnings to avoid $\mathrm{CHO}$ intake during the hour before endurance exercise have become part of sports nutrition dogma (Wilmore \& Costill, 1994; Inge \& Brukner, 1986). However, a review of the literature reveals that this is the only study to find reductions in performance capacity after the ingestion of $\mathrm{CHO}$ in the hour before exercise. Other investigations have found either no detrimental effect or improvements in performance ranging from 7 to $20 \%$ (Table 1).

While a few individuals may experience an exaggerated and detrimental response to the hyperinsulinaemia associated with pre-exercise feedings, these symptoms may be overcome by manipulating the timing of CHO feedings, or by choosing CHO sources that produce a minimal glycaemic-insulinaemic response. Such $\mathrm{CHO}$ would include fructose (Hargreaves et al. 1987) or CHO-rich foods with a low glycaemic index (GI). Because the ingestion of low-GI CHO foods produce less metabolic disturbances before and during 


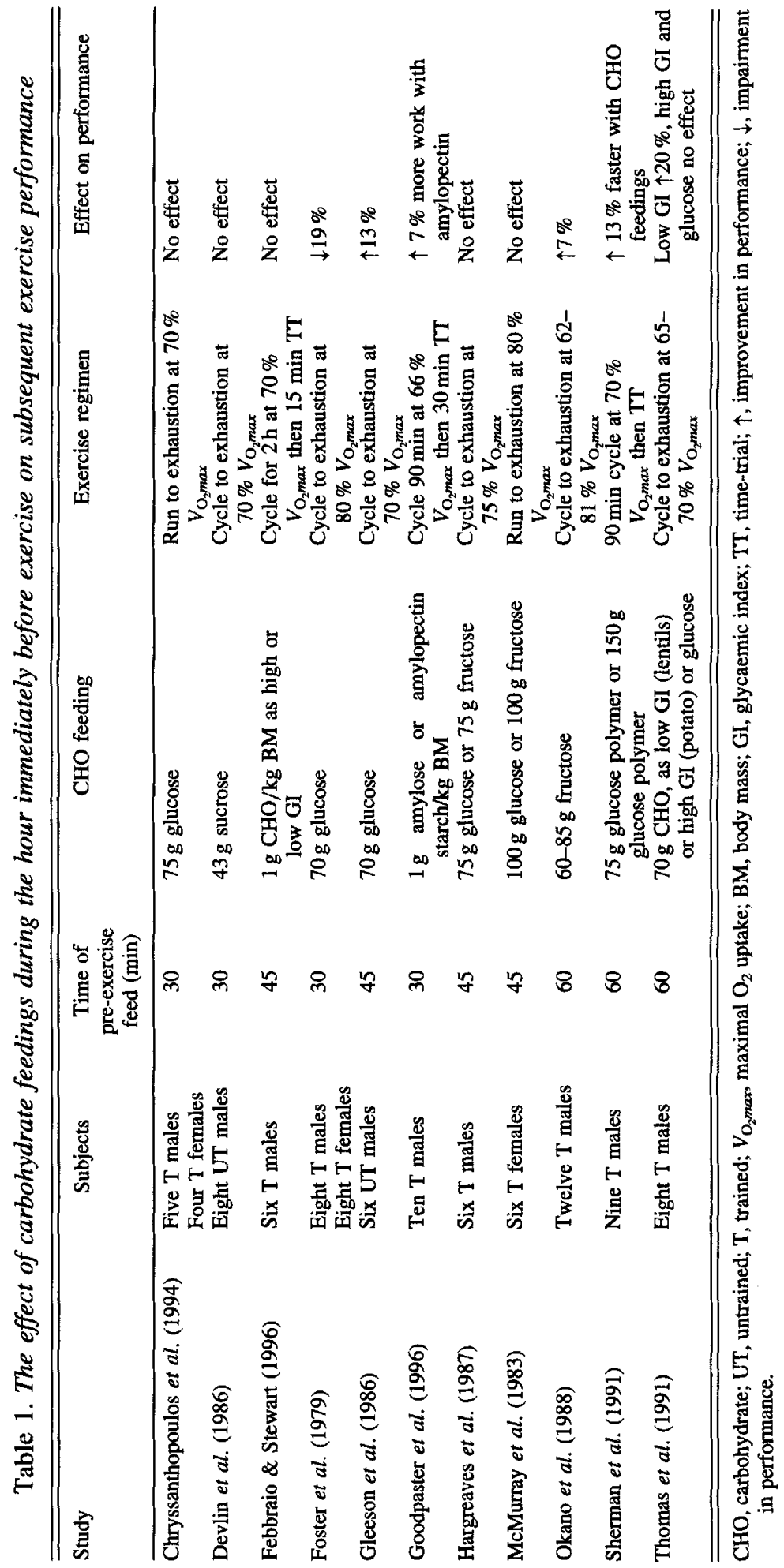


exercise compared with the intake of the same quantity of high-GI CHO (Jenkins et al. 1984), they have recently been promoted as the preferred pre-exercise meal choice (Thomas et al. 1991). However, further research is needed to confirm clear benefits from eating low-GI pre-event meals on exercise performance in all athletes. Indeed, a recent study has reported no differences in performance following ingestion of either low- or high-GI pre-exercise feedings (Febbraio \& Stewart, 1996).

The 'bottom line' for the majority of athletes is that metabolic perturbations associated with the intake of any type of $\mathrm{CHO}$ in the hour before exercise are transient, of little physiological significance, and are off-set by the increased CHO availability. Hence, the benefits and the practical issues associated with pre-exercise feedings should be judged according to the situation and the individual athlete. In some cases an athlete may need to eat before a prolonged training session or competition in order to prevent hunger during the subsequent exercise bout. The universal challenge is to try and ensure that such feedings do not cause excessive fullness, or result in gastrointestinal discomfort (e.g. vomiting, diarrhoea) during exercise. Excessive stomach fullness caused by the ingestion of large volumes of fluid before intense exercise is not only associated with gastrointestinal problems, but also an impairment in exercise performance (Robinson et al. 1995).

In general, 3-4 h may be needed for the digestion of a large CHO-rich, low-fat meal. On the other hand, a smaller CHO-rich snack or a CHO-rich drink may be consumed without gastric disadvantages $30-90$ min before exercise; this may be a more suitable choice for athletes who are competing in early morning events, or as a 'top up' when there is a long gap between the last meal and the exercise session. Athletes undertaking very early training sessions typically do not consume $\mathrm{CHO}$ before the session, judging time and gastrointestinal comfort to be of greater importance than their liver glycogen status. In practice, many athletes are unable to 'work backwards' from the exercise session to consume the theoretically ideal pre-exercise meal programme; instead the 'best possible' plan is usually chosen.

\section{INCREASING CARBOHYDRATE AVAILABILITY DURING EXERCISE: EFFECT OF TIME OF FEEDINGS ON METABOLISM AND ATHLETIC PERFORMANCE}

There is now strong evidence that increasing the availability of $\mathrm{CHO}$ during prolonged, moderate-intensity exercise can improve work capacity. The majority of well-controlled trials employing either prolonged cycling (Brooke et al. 1975; Bjorkman et al. 1984; Coyle et al. 1986; Blom et al. 1987; Coggan \& Coyle, 1987, 1988, 1989; Anantaraman et al. 1995; Below et al. 1995; Jeukendrup et al. 1997) or treadmill running (Macaraeg, 1983; Sasaki et al. 1987; Williams et al. 1990) have shown significant improvements in exercise 'performance' with $\mathrm{CHO}$ ingestion (Table 1). Even when there was no significant positive effect of CHO ingestion on exercise capacity (Felig et al. 1982; Fruth \& Gisolfi, 1983; Inge \& Brukner, 1986; Flynn et al. 1987; Riley et al. 1988), neither was performance adversely affected by increasing the availability of $\mathrm{CHO}$ (Table 1 ).

Although there is some evidence that increasing CHO availability decreases rates of muscle glycogen utilization (Hargreaves et al. 1984; Erickson et al. 1987), the majority of studies show no effect of CHO feedings during moderate-intensity exercise on muscle glycogenolysis (Coyle et al. 1985; Fielding et al. 1985; Flynn et al. 1987; Hargreaves \& Briggs, 1988; Noakes et al. 1988; Bosch et al. 1993). Rather, the major effect of CHO feedings during prolonged exercise is to maintain plasma glucose concentration, sustain high rates of CHO oxidation, and spare liver glycogen (Bosch et al. 1993). 
In order to study the contribution of ingested $\mathrm{CHO}$ to total energy metabolism, isotopes such as naturally-labelled $\left[{ }^{13} \mathrm{C}\right]$ glucose (Saris et al. 1993; Wagenmakers et al. 1993) or radioactive ${ }^{14} \mathrm{C}$-labelled CHO (Hawley et al. 1992b) must be added to the food or drink. Reviews of isotope studies which have taken into consideration methodological problems involved with these techniques reveal that there are no physiologically-important differences in the maximal rates of ingested $\mathrm{CHO}$ oxidation from a variety of moderate to high-GI CHO sources ingested during prolonged, moderate-intensity exercise. With the exception of fructose, exogenous $\mathrm{CHO}$ is ultimately oxidized at a peak rate of $1 \mathrm{~g} / \mathrm{min}$ (Hawley et al. 1992a; Guezennec, 1995).

Rates of ingested CHO oxidation also appear to be unaffected by the use of different feeding schedules. Comparison of the single bolus (total glucose intake approximately 50$100 \mathrm{~g}$ ) with the multiple glucose feeding studies (total glucose intake approximately 100 $220 \mathrm{~g}$ ) show that the amount of ingested $\mathrm{CHO}$ oxidized in the first hour of exercise, and the peak rates of ingested glucose oxidation are quite similar. With most of the feeding schedules approximately $20 \mathrm{~g}$ of ingested glucose was oxidized in the first hour and, in all cases, the peak rate of ingested CHO oxidation did not exceed $1 \mathrm{~g} / \mathrm{min}$ (Hawley et al. 1992a). Since repetitive feedings would be expected to accelerate the delivery of glucose from the stomach to the duodenum (Mitchell \& Voss, 1991; Noakes et al. 1991), the similar peak rates of exogenous glucose oxidation after single and multiple feedings of moderate $(50-200 \mathrm{~g})$ glucose loads suggest that ingested CHO oxidation is probably limited by its rate of absorption from the intestine and passage via the liver into the systemic circulation (Hawley et al. 1994).

With regard to the effect of the frequency and dose of CHO feedings on exercise performance, Fielding $e t$ al. (1985) studied healthy subjects who ingested approximately $10 \mathrm{~g} \mathrm{CHO}$ at $30 \mathrm{~min}$ intervals, or approximately $21 \mathrm{~g} \mathrm{CHO}$ at $60 \mathrm{~min}$ intervals throughout $4 \mathrm{~h}$ of cycling exercise. Although the total dosage of $\mathrm{CHO}$ was identical in the two trials, $\mathrm{CHO}$ feedings did not affect either the rate of muscle glycogen utilization, nor a sprint-ride to exhaustion at the end of the prolonged, submaximal exercise bout.

Whereas feeding frequency does not appear to influence the rates of either endogenous or ingested $\mathrm{CHO}$ oxidation during prolonged exercise, withholding $\mathrm{CHO}$ until late in an exercise bout will impair performance. McConell et al. (1996) studied eight well-trained men who rode for $2 \mathrm{~h}$ at $70 \%$ of $V_{\mathrm{O}_{2} \max }$, followed immediately by a $15 \mathrm{~min}$ 'performance' ride. Subjects ingested either $250 \mathrm{ml}$ of a $70 \mathrm{~g} \mathrm{CHO} / 1$ solution every $15 \mathrm{~min}$ throughout exercise, or a placebo for $90 \mathrm{~min}$ followed by a $210 \mathrm{~g} \mathrm{CHO} / 1$ beverage at 91,105 and $120 \mathrm{~min}$. Despite starting the performance ride with significantly elevated plasma glucose concentrations when $\mathrm{CHO}$ was ingested late in exercise, the total work performed during the 15 min time-trial was significantly higher when subjects had been fed $\mathrm{CHO}$ throughout exercise. These results suggest that $\mathrm{CHO}$ ingestion improves performance through mechanisms other than, or in addition to, an increased $\mathrm{CHO}$ availability to the contracting muscles.

Of course, practical considerations may dictate the timing and frequency of feedings that athletes can follow. During endurance events, energy replacement occurs while the athlete is literally 'on the run,' and might only be limited by consideration of the time lost in stopping or slowing down to consume food or fluid, or the impact of such ingestion on gastrointestinal discomfort. On the other hand, in many team sports the opportunity to ingest fluid is governed by the official rules of the sport and limited to formal breaks or during informal injury stoppages (Burke \& Hawley, 1997b). In this regard, it is interesting to observe the evolution of the International Amateur Athletic Federation (IAAF) rules governing the intake of food and fluid during prolonged exercise (Fig. 1). Since the first 


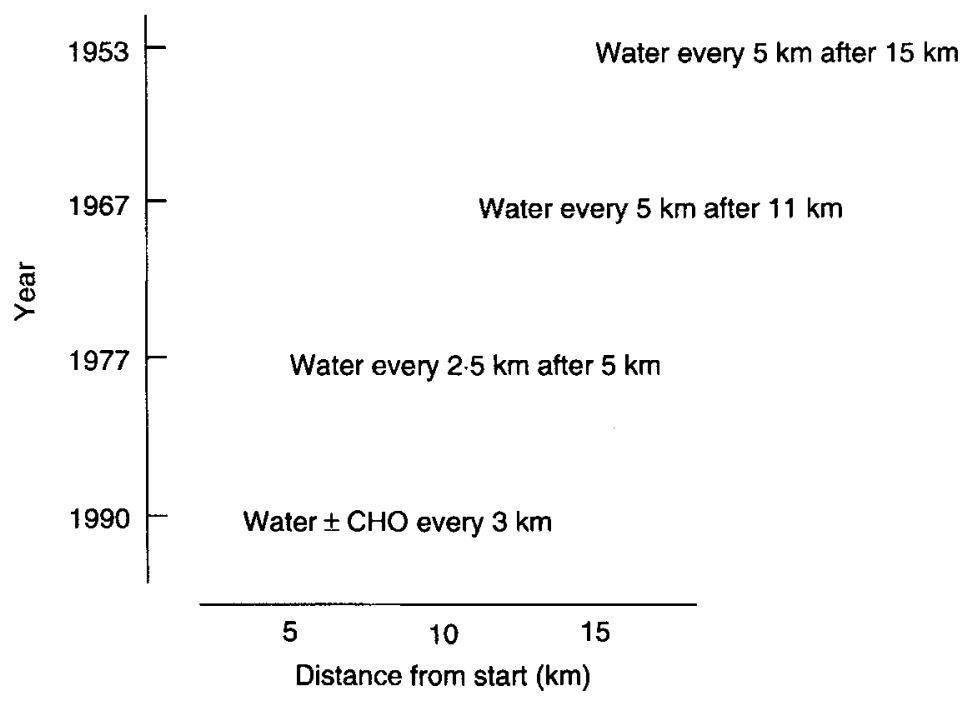

Fig. 1. The historical evolution of the International Amateur Athletic Federation rules governing the intake of food and fluids during long-distance running. Since 1953 the timing and frequency of opportunity for feedings has increased dramatically. $\pm \mathrm{CHO}$, with or without carbohydrate. (Redrawn from Hawley et al. 1995.)

official reference in 1953 to 'nutrient' replacement during long-distance running, both the opportunity and timing of feedings has increased significantly.

\section{INCREASING CARBOHYDRATE AVAILABILITY POST-EXERCISE: EFFECT OF TIME AND TYPE OF FEEDINGS ON RECOVERY}

Previously it was thought that up to $48 \mathrm{~h}$ was necessary to restore muscle and liver glycogen stores to normal levels following exercise-induced depletion (Piehl, 1974; Piehl et al. 1974). Now it is commonly accepted that glycogen repletion can be accomplished within $24 \mathrm{~h}$ providing the amount and timing of $\mathrm{CHO}$ is optimal.

To determine the effect of the timing of $\mathrm{CHO}$ intake after an exercise-induced depletion regimen, Ivy et al. (1988) had trained subjects lower their muscle glycogen stores by intermittent low-and-high-intensity exercise, and then ingest $\mathrm{CHO}$ at various times after exercise. The rate of muscle glycogen storage was highest $(7.7 \mathrm{mmol} / \mathrm{kg}$ wet weight (ww) per $h$ ) for the first $2 \mathrm{~h}$ period when subjects ingested CHO immediately post exercise but was lower $(4.1 \mathrm{mmol} / \mathrm{kg}$ ww per $\mathrm{h})$ when CHO consumption was delayed for $2 \mathrm{~h}$ after exercise had stopped. When little or no CHO was consumed for several hours, there was minimal glycogen re-synthesis $(2.5 \mathrm{mmol} / \mathrm{kg}$ ww per h) (Ivy et al. 1988). Although interpretation of these data have focused on the higher rates of glycogen synthesis in the immediate post-exercise period, compared with that several hours later, it is unlikely that these differences are physiologically important. Perhaps the most significant finding is that failure to consume CHO in the immediate phase of post-exercise recovery results in very low rates of glycogen restoration until feeding occurs. Hence, the importance of early intake of $\mathrm{CHO}$ following strenuous exercise is to avoid delaying the provision of substrate to the muscle cell, more than to take advantage of a period of moderately-enhanced glycogen synthesis. This strategy is most important when there is only $4-8 \mathrm{~h}$ of recovery 
between exercise sessions and the athlete wishes to maximize glycogen storage. As the time for recovery becomes longer (i.e. $>24 \mathrm{~h}$ ) it is likely that any small differences in the early rates of glycogen re-synthesis are unimportant.

The question of whether CHO intake during recovery is best consumed as large feedings or as a series of snacks has been addressed by several groups. The results of these studies show that as long as the total amount of $\mathrm{CHO}$ ingested is sufficient, the repletion of muscle glycogen synthesis is unaffected by the frequency of food intake: muscle glycogen storage after $24 \mathrm{~h}$ was similar when $525 \mathrm{~g}$ CHO was fed as two or seven meals (Costill et al. 1981 ) or when $10 \mathrm{~g} \mathrm{CHO} / \mathrm{kg} \mathrm{BM}$ was consumed as either four large meals or sixteen snacks (Burke et al. 1996).

The effects of the type (low or high GI) and form (solid or liquid) of CHO ingested during the post-exercise recovery period on the rates of muscle glycogen synthesis have also been investigated. Whereas glucose and sucrose have been shown to produce similar rates of muscle glycogen recovery (Blom et al. 1987; Ivy et al. 1988; Reed et al. 1989), the ingestion of similar amounts of fructose promotes a much lower rate of glycogen storage (Blom et al. 1987). However, studies of single nutrient feedings of mono- or disaccharides during the first $6 \mathrm{~h}$ of recovery hardly deal with the more relevant issues of food intake and everyday nutrition goals. The results of studies of muscle glycogen re-synthesis with different $\mathrm{CHO}$ foods have produced conflicting results, principally because of the confusing classification of CHO foods into 'simple' and 'complex' types. Such nomenclature is based on structural considerations rather than true metabolic or physiological properties (Jenkins et al. 1984). For example, Costill et al. (1981) reported that during the first $24 \mathrm{~h}$ of recovery after exhaustive running, both 'simple' and 'complex' CHO foods produced comparable rates of muscle glycogen synthesis. Over the subsequent $24 \mathrm{~h}$ period, the consumption of 'complex' $\mathrm{CHO}$ resulted in a significantly higher rate of glycogen storage. More recent data, however, suggest that rates of muscle glycogen synthesis were significantly greater during the first $6 \mathrm{~h}$ post-exercise when 'simple' rather than 'complex' CHO foods were ingested, possibly as a consequence of the higher plasma insulin concentration following ingestion of the 'simple' CHO (Kiens et al. 1990).

It has been hypothesized that $\mathrm{CHO}$ foods with a moderate-to-high GI should take priority in the post-exercise diet, and that foods with a low GI should not make up more than one-third of recovery meals (Coyle, 1992). Results of a recent study support this notion. Burke et al. (1993) reported that a diet comprising high-GI CHO foods promoted greater glycogen storage than an equal amount of CHO eaten as low-GI foods in the $24 \mathrm{~h}$ period after strenuous exercise. On the other hand, the consumption of CHO in both solid or liquid form appears to be equally efficient in providing substrate for muscle glycogen synthesis (Keizer et al. 1986; Reed et al. 1989).

\section{SUMMARY AND DIRECTIONS FOR FUTURE RESEARCH}

Some athletes have energy expenditures two to three times greater than untrained massmatched individuals, with up to $40 \%$ of their energy expenditure being the cost of training. In situations of increased energy requirements they adopt a high frequency of food consumption, often eating one-third of their total energy intake as between meal snacks throughout the day. Because $\mathrm{CHO}$ requirements are high, and because endogenous $\mathrm{CHO}$ reserves are limited, athletes undertaking prolonged, strenuous exercise should seek to maximize CHO availability at all times. This can be achieved by the ingestion of preexercise $(1-4 \mathrm{~h})$ meals, CHO feedings at regular intervals throughout exercise, and an 
aggressive post-exercise nutritional strategy involving the consumption of $\mathrm{CHO}$ as soon as practical after exercise.

Future research should fine tune the timing of $\mathrm{CHO}$ intake pre-, during and postexercise. In particular, studies which measure the effect of these strategies on actual performance are needed. Applied research, using experimental designs that mimic true sporting activities, and in which athletes actually eat common foods, is of high priority, as practical considerations more often than not dictate the athletes' ingestion regimen.

There are many other frontiers of sports nutrition research in which the timing of the intake of specific foods and nutrients may prove to be important, including:

(1) the role of endogenous and exogenous fat as fuel for exercise metabolism. Can the intake of medium-chain triacylglycerols during exercise be of benefit to sports performance, and if so, what is the optimal timing of such feedings? Is repletion of intramuscular triacylglycerol an important issue for post-exercise recovery, and if so, what is the optimal timing of such feedings?

(2) optimizing protein synthesis for gain of lean BM. Does the timing of food-nutrient intake and post-exercise eating patterns affect protein synthesis?

(3) immune system and recovery. Does the timing of food-nutrient intake during and after exercise optimize immune responses (e.g. antioxidants)?

\section{REFERENCES}

American Dietetic Association (1993). Position stand of the American Dietetic Association and the Canadian Dietetic Association: nutrition for physical fitness and athletic performance for adults. Journal of American Dietetic Association 93, 691-696.

Anantaraman, R., Carmines, A. A., Gaesser, G. A. \& Weltman, A. (1995). Effects of carbohydrate supplementation on performance during 1 hour of high-intensity exercise. International Journal of Sports Medicine 16, 461-465.

Barry, A., Cantwell, T., Doherty, F., Folan, J. C., Ingoldsby, M., Kevany, J. P., O'Broin, J. D., O'Connor, H., O'Shea, B., Ryan, B. A. \& Fimls, J. V. (1981). A nutritional study of Irish athletes. British Journal of Sports Medicine 15, 99-109.

Below, P. R., Mora-Rodriguez, R., Gonzalez-Alonso, J. \& Coyle, E. F. (1995). Fluid and carbohydrate ingestion independently improve performance during $1 \mathrm{~h}$ of intense cycling. Medicine and Science in Sports and Exercise 27, 200-210.

Bjorkman, O., Sahlin, K., Hagenfeldt, L. \& Wahren, J. (1984). Influence of glucose and fructose ingestion on the capacity for long-term exercise in well-trained men. Clinical Physiology 4, 4883-4494.

Blom, P. C. J., Hostmark, A. T., Vaage, O., Vardal, K. R. \& Maehlum, S. (1987). Effect of different postexercise sugar diets on the rate of muscle glycogen synthesis. Medicine and Science in Sports and Exercise 19, 491-496.

Bosch, A. N., Dennis, S. C. \& Noakes, T. D. (1993). Influence of carbohydrate loading on fuel substrate turnover and oxidation during prolonged exercise. Journal of Applied Physiology 74, 1921-1927.

Brooke, J. D., Davies, G. J. \& Green, L. F. (1975). The effects of normal and glucose syrup work diets on the performance of racing cyclists. Journal of Sports Medicine 15, 257-265.

Brotherhood, J. R. (1984). Nutrition and sports performance. Sports Medicine 1, 350-389.

Burke, L. M., Collier, G. R., Davis, P. G., Fricker, P. A., Sanigorski, A. J. \& Hargreaves, M. (1996). Muscle glycogen storage after prolonged exercise: effect of the frequency of carbohydrate feedings. American Journal of Clinical Nutrition 64, 115-119.

Burke, L. M., Collier, G. R. \& Hargreaves, M. (1993). Muscle glycogen storage after prolonged exercise: effect of glycemic index of carbohydrate feedings. Joumal of Applied Physiology 75, 1019-1023.

Burke, L. M., Gollan, R. A. \& Read, R. S. D. (1991). Dietary intakes and food use of groups of elite Australian male athletes. International Journal of Sports Nutrition 1, 378-394.

Burke, L. M. \& Hawley, J. A. (1997a). Nutritional strategies for athletic performance. In Medical Problems in Athletes, [K. B. Fields and P. A. Fricker, editors]. New York: Blackwell Science (In the Press).

Burke, L. M. \& Hawley, J. A. (1997b). Fluid balance in team sports: guidelines for optimal practices. Sports Medicine (In the Press).

Butterworth, D. E., Nieman, D. C., Butler, J. V. \& Herring, J. L. (1994). Food intake patterns of marathon runners. International Joumal of Sports Nutrition 4, 1-7. 
Chryssanthopoulos, C., Hennessy, L. C. M. \& Williams, C. (1994). The influence of pre-exercise glucose ingestion on endurance running capacity. British Journal of Sports Medicine 28, 105-109.

Coggan, A. R. \& Coyle, E. R. (1987). Reversal of fatigue during prolonged exercise by carbohydrate infusion or ingestion. Journal of Applied Physiology 63, 2388-2395.

Coggan, A. R. \& Coyle, E. F. (1988). Effect of carbohydrate feedings during high-intensity exercise. Journal of Applied Physiology 65, 1703-1709.

Coggan, A. R. \& Coyle, E. F. (1989). Metabolism and performance following carbohydrate ingestion late in exercise. Medicine and Science in Sports and Exercise 21, 59-65.

Costill, D. L., Sherman, W. M., Fink, W. J., Maresh, C., Witten, M. \& Miller, J. M. (1981). The role of dietary carbohydrates in muscle glycogen resynthesis after strenuous running. American Journal of Clinical Nutrition 34, 1831-1836.

Coyle, E. F. (1992). Timing and method of increased carbohydrate intake to cope with heavy training, competition and recovery. In Food, Nutrition and Sports Performance, pp. 35-62 [C. Williams and J. T. Devlin, editors]. London: E \& F Spon.

Coyle, E. F., Coggan, A. R., Hemmert, M. K. \& Ivy, J. L. (1986). Muscle glycogen utilisation during prolonged strenuous exercise when fed carbohydrate. Journal of Applied Physiology 61, 165-172.

Coyle, E. F., Coggan, A. R., Hemmert, M. K., Lowe, R. C. \& Walters, T. J. (1985). Substrate usage during prolonged exercise following a pre-exercise meal. Journal of Applied Physiology 59, 429-433.

Danforth, E. (1985). Diet and obesity. American Journal of Clinical Nutrition 41, 1132-1145.

Devlin, J. T., Calles-Escandon, J. \& Horton, E. S. (1986). Effects of preexercise snack feeding on endurance cycle exercise. Journal of Applied Physiology 60, 980-985.

De Wijn, J. F. \& Van Erp-Baart, M. (1980). Food pattern, body composition and physical condition of heavy weight competition-rowers. Voeding 41, 13-18.

Erickson, M. A., Schwarzkopf, R. J. \& McKenzie, R. D. (1987). Effects of caffeine, fructose, and glucose ingestion on muscle glycogen utilisation during exercise. Medicine and Science in Sports and Exercise 19, 579-583.

Febbraio, M. A. \& Stewart, K. L. (1996). Carbohydrate feedings before prolonged exercise: effect of glycemic index on muscle glycogenolysis and exercise performance. Journal of Applied Physiology 81, 1115-1120.

Felig, P., Cherif, A., Minigawa, A. \& Wahren, J. (1982). Hypoglycaemia during prolonged exercise in normal men. New England Journal of Medicine 306, 895-900.

Fielding, R. A., Costill, D. L., Fink, W. J., King, D. S., Hargreaves, M. \& Kovaleski, J. E. (1985). Effect of carbohydrate feeding frequencies and dosage on muscle glycogen use during exercise. Medicine and Science in Sports and Exercise 17, 472-476.

Flynn, M. G., Costill, D. L., Hawley, J. A., Fink, W. J., Neufer, P. D., Fielding, R. A. \& Sleeper, M. D. (1987) Influence of selected carbohydrate drinks on cycling performance and glycogen use. Medicine and Science in Sports and Exercise 19, 37-40

Fogelholm, M., Rehunen, S., Gref, C.-G., Laakso, J. T., Lehto, J., Ruokonen, I. \& Himberg, J.-J. (1992). Dietary intake and thiamin, iron, and zinc status in elite Nordic skiers during different training periods. International Journal of Sports Nutrition 2, 351-365.

Foster, C., Costill, D. L. \& Fink, W. J. (1979). Effects of preexercise feedings on endurance performance. Medicine and Science in Sports 11, 1-5.

Fruth, J. M. \& Gisolfi, C. V. (1983). Effects of carbohydrate consumption on endurance performance: fructose versus glucose. In Nutrient Utilization During Exercise, pp. 68-75 [E. L. Fox, editor]. Columbus, OH: Ross Laboratories.

Gleeson, M., Maughan, R. J. \& Greenhaff, P. L. (1986). Comparison of the effects of pre-exercise feeding of glucose, glycerol and placebo on endurance performance and fuel homeostasis in man. European Journal of Applied Physiology 55, 645-653.

Goodpaster, B. H., Costill, D. L., Fink, W. J., Trape, T. A., Joszi, A. C., Starling, R. D. \& Trappe, S. W. (1996). The effects of pre-exercise starch ingestion on endurance performance. International Journal of Sports Medicine 17, 366-372.

Guezennec, C. Y. (1995). Oxidation rates, complex carbohydrates and exercise. Sports Medicine 19, $365-372$.

Hargreaves, M. \& Briggs, C. A. (1988). Effect of carbohydrate ingestion on exercise metabolism. Journal of Applied Physiology 65, 1553-1555.

Hargreaves, M., Costill, D. L., Coggan, A., Fink, W. J. \& Nishibata, I. (1984). Effect of carbohydrate feedings on muscle glycogen utilisation and exercise performance. Medicine and Science in Sports and Exercise 16, 219-222.

Hargreaves, M., Costill, D. L., Fink, W. J., King, D. S. \& Fielding, R. A. (1987). Effect of pre-exercise carbohydrate feedings on endurance cycling performance. Medicine and Science in Sports and Exercise 19, 33-36.

Hawley, J. A., Bosch, A. N., Weltan, S. M., Dennis, S. C. \& Noakes, T. D. (1994). Glucose kinetics during prolonged exercise in euglycaemic and hyperglycaemic subjects. Pflugers Archiv 426, 378-386.

Hawley, J. A., Dennis, S. C. \& Noakes, T. D. (1992a). Oxidation of carbohydrate ingested during prolonged endurance exercise. Sports Medicine 14, 27-42. 
Hawley, J. A., Dennis, S. C. \& Noakes, T. D. (1995). Carbohydrate, fluid and electrolyte requirements during prolonged exercise. In Sports Nutrition. Minerals and Electrolytes, pp. 235-265 [C. V. Kies and J. A. Driskell, editors]. Boca Raton: CRC Press.

Hawley, J. A., Dennis, S. C., Nowitz, A., Brouns, F. \& Noakes, T. D. (1992b). Exogenous carbohydrate oxidation from maltose and glucose ingested during prolonged exercise. European Journal of Applied Physiology 64, 523-527.

Hawley, J. A. \& Hopkins, W. G. (1995). Aerobic glycolytic and aerobic lipolytic power systems. A new paradigm with implications for endurance and ultra-endurance events. Sports Medicine 19, 240-250.

Hawley, J. A. \& Williams, M. M. (1991). Dietary intakes of age-group swimmers. British Journal of Sports Medicine 25, 154-158.

Inge, K. \& Brukner, K. (1986). Food For Sport. A Nutrition Guide for Australian Sportsmen, Sportswomen, Coaches and Parents, pp. 95-96. Melbourne, Australia: William Heinemann.

Ivy, J. L., Katz, A. L., Cutler, C. L., Sherman, W. M. \& Coyle, E. F. (1988). Muscle glycogen synthesis after exercise: effect of time of carbohydrate ingestion. Journal of Applied Physiology 65, 1480-1485.

Jenkins, D. J. A., Wolever, T. M. S., Jenkins, A. L., Josse, R. G. \& Wong, G. S. (1984). The glycaemic response to carbohydrate foods. Lancet ii, 388-391.

Jeukendrup, A. E., Brouns, F., Wagenmakers, A. J. M. \& Saris, W. H. M. (1997) Carbohydrate-electrolyte feedings improve $1 \mathrm{~h}$ time-trial cycling performance. International Journal of Sports Medicine (In the Press).

Keizer, H., Kuipers, H., van Kranenburg, G. \& Geurten, P. (1986). Influence of liquid and solid meals on muscle glycogen resynthesis, plasma fuel hormone response, and maximal physical working capacity. International Journal of Sports Medicine 8, 99-104.

Khoo, C.-S., Rawson, N. E., Robinson, M. L. \& Stevenson, R. J. (1987). Nutrient intake and eating habits of triathletes. Annals of Sports Medicine 3, 144-150.

Kiens, B., Raben, A. B., Valeur, A. K. \& Richter, E. A. (1990). Benefit of dietary simple carbohydrates on the early postexercise muscle glycogen repletion in male athletes. Medicine and Science in Sports and Exercise 22, Suppl., S88.

Kirsch, K. A. \& Von Ameln, H. (1981). Feeding patterns of endurance athletes. European Journal of Applied Physiology 47, 97-208.

Lindeman, A. K. (1990). Eating and training habits of triathletes: a balancing act. Joumal of American Dietetic Association 90, 993-995.

Macaraeg, P. V. J. (1983). Influence of carbohydrate electrolyte ingestion on running endurance. In Nutrient Utilization During Exercise, pp. 91-96 [E. L. Fox, editor]. Columbus, OH: Ross Laboratories.

McConell, G., Kloot, K. \& Hargreaves, M. (1996). Effect of timing of carbohydrate ingestion on endurance exercise performance. Medicine and Science in Sports and Exercise 28, 1300-1304.

McMurray, R. G., Wilson, J. R. \& Kitchell, B. S. (1983). The effects of fructose and glucose on high intensity endurance performance. Research Quarterly for Exercise and Sport 54, 156-162.

Mitchell, J. B. \& Voss, K. W. (1991). The influence of volume on gastric emptying and fluid balance during prolonged exercise. Medicine and Science in Sports and Exercise 23, 314-319.

Neufer, P. D., Costill, D. L., Flynn, M. G., Kirwan, J. P., Mitchell, J. B. \& Houmard, J. (1987). Improvements in exercise performance: effects of carbohydrate feedings and diet. Journal of Applied Physiology 62, 983988.

Noakes, T. D., Lambert, E. V., Lambert, M. I., McArthur, P. S., Myburgh, K. H. \& Benade, A. J. S. (1988) Carbohydrate ingestion and muscle glycogen depletion during marathon and ultramarathon racing. European Journal of Applied Physiology 57, 482-489.

Noakes, T. D., Rehrer, N. J. \& Maughan, R. J. (1991). The importance of volume in regulating gastric emptying. Medicine and Science in Sports and Exercise 23, 307-313.

Okano, G., Takeda, H., Morita, I., Katoh, M., Mu, Z. \& Miyake, S. (1988). Effect of pre-exercise fructose ingestion on endurance performance in fed men. Medicine and Science in Sports and Exercise 20, $105-109$.

Piehl, K. (1974). Time course for refilling of glycogen stores in human muscle fibers following exercise-induced glycogen depletion. Acta Physiologica Scandinavica 90, 297-302.

Piehl, K., Adolfsson, S. \& Nazar, K. (1974). Glycogen storage and glycogen synthase activity in trained and untrained muscle of man. Acta Physiologica Scandinavica 90, 779-788.

Reed, M. J., Brozinicle, J. T., Lee, M. C. \& Ivy, J. L. (1989). Muscle glycogen storage post exercise: effect of mode of carbohydrate administration. Journal of Applied Physiology 66, 720-726.

Riley, M. L., Israel, R. G., Holbert, D., Tapscott, E. B. \& Dohm, G. L. (1988). Effect of carbohydrate ingestion on exercise endurance and metabolism after a 1-day fast. International Journal of Sports Medicine 9, 320 324.

Robinson, T. A., Hawley, J. A., Palmer, G. S., Wilson, G. R., Gray, D. A., Noakes, T. D. \& Dennis, S. C. (1995). Water ingestion does not improve 1-h cycling performance in moderate ambient temperatures. European Journal of Applied Physiology 71, 153-160.

Saltin, B. \& Karlsson, J. (1971). Muscle glycogen utilization during work of different intensities. In Muscle Metabolism During Exercise, pp. 289-300 [B. Pernow and B. Saltin, editors]. New York: Plenum Press. 
Saris, W. H. M., Goodpaster, B. H., Jeukendrup, A. E., Brouns, F., Halliday, D. \& Wagenmakers, A. J. M. (1993). Exogenous carbohydrate oxidation from different carbohydrate sources during exercise. Journal of Applied Physiology 75, 2168-2172.

Saris, W. H. M., Van Erp-Baart, M. A., Brouns, F., Westerterp, K. R. \& Ten Hoor, F. (1989). Study on food intake and energy expenditure during extreme sustained exercise: the Tour de France. International Journal of Sports Medicine 10, S26-S31.

Sasaki, H., Maeda, J., Usui, S. \& Ishiko, T. (1987). Effect of sucrose and caffeine ingestion on performance of prolonged strenuous running. International Journal of Sports Medicine 8, 261-265.

Sherman, W. M., Brodowicz, G., Wright, D. A., Allen, W. K., Simonsen, J. \& Dernbach, A. (1989). Effects of $4 \mathrm{~h}$ preexercise carbohydrate feedings on cycling performance. Medicine and Science in Sports and Exercise 21, 598-604.

Sherman, W. M., Costill, D. L., Fink, W. J. \& Miller, J. M. (1981). Effect of diet-exercise manipulation on muscle glycogen and its subsequent utilisation during performance. International Journal of Sports Medicine 2, 114-118.

Sherman, W. M., Peden, M. C. \& Wright, D. A. (1991). Carbohydrate feedings $1 \mathrm{~h}$ before exercise improves cycling performance. American Journal of Clinical Nutrition 54, 866-870.

Short, S. H. \& Short, W. R. (1983). Four-year study of university athletes' dietary intake. Journal of American Dietetic Association 82, 632-645.

Thomas, D. E., Brotherhood, J. R. \& Brand, J. C. (1991). Carbohydrate feeding before exercise: effect of glycemic index. International Journal of Sports Medicine 12, 180-186.

Van Erp-Baart, A. M. J., Saris, W. H. M., Binkhorst, R. A., Vos, J. A. \& Elvers, J. W. H. (1989). Nationwide survey on nutritional habits in elite athletes. Part I. Energy, carbohydrate, protein, and fat intake. International Journal of Sports Medicine 10, S3-S10.

Wagenmakers, A. J. M., Brouns, F., Saris, W. H. M. \& Halliday, D. (1993). Oxidation rates of orally ingested carbohydrates during prolonged exercise in man. Journal of Applied Physiology 75, 2774-2780.

Williams, C., Nute, M. G., Broadbank, L. \& Vinall, S. (1990). Influence of fluid intake on endurance running performance: a comparison between water, glucose and fructose solutions. European Journal of Applied Physiology 60, 112-119.

Wilmore, J. \& Costill, D. L. (1994). Physiology of Sport and Exercise. Champaign, IL: Human Kinetics.

Wright, D. A., Sherman, W. M. \& Dernbach, A. R. (1991). Carbohydrate feedings before, during, or in combination improve cycling endurance performance. Journal of Applied Physiology 71, 1082-1088. 